\title{
Hypoglycemia associated with non-islet cell tumors
}

\author{
Minireview
}

D. KANTAROVA, I. SAGOVA*, M. STANCIK, J. SADLONOVA

Department of Internal Medicine 1, Jessenius Medical Faculty of Comenius University and University Hospital Martin

${ }^{*}$ Correspondence: iva.sagova@gmail.com

Received April 29, 2015 / Accepted July 9, 2015

\begin{abstract}
Tumor hypoglycemia is rare but life-threatening medical condition which may be associated with insulinoma and non-islet cell tumors (mainly of mesenchymal origin). The pathogenesis is connected with abnormal processing of insulin-like growth factor-2 (IGF-2) precursor and production of pathognomic „big“ IGF-2 - incompletely processed posttranslational precursor of IGF-2, which is responsible for hypoglycemia. Other typical laboratory features include low level of fasting glucose and C-peptide, low IGF-1 and increased IGF-2 : IGF-1 ratio. Although paraneoplastic hypoglycemia is often present in patients with already diagnosed malignancy, it is necessary to consider this possibility in patients having unclear and inexplicable hypoglycemia. The adequate treatment can significantly reduce the symptoms and improve the quality of life.
\end{abstract}

Key words: tumor hypoglycemia, non-islet cell tumor, insulin-like growth factor

Hypoglycemia is a medical emergency which is usually associated with the presence of diabetes mellitus or with the treatment of this disease. However, there are also several other pathomechanisms and it may be also a serious complication of malignancy caused by both pancreatic islet cell tumors producing insulin (insulinomas) and non-islet cell tumors (Table 1) $[1,2]$.

\section{Incidence of the disease}

Non-islet cell tumor hypoglycemia (NICTH) is a rare feature of paraneoplastic syndrome - in the review by Bodnar et al. (2013) there are nearly 290 cases of NICTH reported in the English language medical literature in the past quarter century [1]. Being a rare disease, the true incidence of NICTH is not known; it is estimated to be one per million people years [3].

This condition should be considered in patients presenting with tumor of mesenchymal origin or less frequently, in malignant epithelial tumors, hematopoietic and neuroendocrine tumors $[4,5]$.

According to the review of this topic by de Groot et al. [6] $41 \%$ are represented by mesenchymal tumors, $43 \%$ by tu- mors of epithelial origin, $1 \%$ of tumors with neuroendocrine and hematopoietic origin and $14 \%$ of unknown origin [6, 7]. However the review of recent reported cases of NICTH identified variety of pathologic diagnoses and widespread anatomic locations of tumors associated with paraneoplastic hypoglycemia $[7,8]$.

Mesenchymal tumors are localized mainly in the retroperitoneum and pelvic areas (65\%) or chest (30\%). Gastrointestinal stromal tumors (GIST) are often associated with hypoglycemia, too. The most common appearance of GIST is stomach $(60-70 \%)$, followed by the small intestine, colon and rectum [9]. The gynecological tumors associated with hypoglycemia are particularly leiomyosarcoma, solitary fibrous tumor and fibrosarcoma [6]. Among others, it is necessary to mention mesothelioma, hemangiopericytoma, solitary fibrous tumors, fibrosarcomas, synovial sarcoma, myxoid liposarcoma, chondrosarcoma, Ewing's sarcoma and undifferentiated pleiomorphic sarcoma. Hypoglycemia may be sometimes also the symptom of fibrous tumor of the pleura (approximately $5 \%$ of patients) - this condition is known as Doege-Potter syndrome [10]. Among primary epithelial tumors, episodes of hypoglycemia were described in patients with large cell ad- 
Table 1. Diseases and pathologic conditons and patomechanism of hypoglycemia [6-8, 15]

\begin{tabular}{|c|c|c|}
\hline \multicolumn{2}{|c|}{ Pathological condition } & Pathogenesis of hypoglycemia \\
\hline \multicolumn{2}{|l|}{ Diabetes mellitus } & Administration of exogenous insulin and/or oral antidiabetic drugs \\
\hline \multicolumn{2}{|c|}{ Gastric by-pass operation } & Rapid emptying of stomach, changed insulin response to absorption of substrates \\
\hline \multicolumn{2}{|l|}{ Alcohol intake } & Inhibition of gluconeogenesis, malnutrition \\
\hline \multicolumn{2}{|c|}{ Primary or secondary adrenal insufficiency } & Defect of gluconeogenesis and glycogenolysis \\
\hline \multicolumn{2}{|c|}{ Advanced liver disease } & Defect of gluconeogenesis and glycogenolysis \\
\hline \multicolumn{2}{|l|}{ Hypothyroidism } & Defect of gluconeogenesis and glycogenolysis \\
\hline \multirow{5}{*}{$\begin{array}{l}\text { Tumor - associated } \\
\text { conditions }\end{array}$} & $\begin{array}{l}\text { Pancreatic islet cell tumors } \\
\text { (or ectopic insulin-producing tumor) }\end{array}$ & Production of endogenous insulin \\
\hline & \multirow{2}{*}{ Non-islet cell tumors } & $\begin{array}{l}\text { Production of substances interfering with glucose metabolism (insulin growth } \\
\text { factor - IGF-1 or }-2 \text {, insulin receptor antibodies) }\end{array}$ \\
\hline & & Production of tumor necrosis factor, interleukin-1 and -6 \\
\hline & Liver tumors & Destruction by massive tumor infiltration \\
\hline & Tumors of adrenal glands & Excess catecholamine production \\
\hline
\end{tabular}

enocarcinoma, hepatocellular carcinoma, renal cell carcinoma, phyllodes tumor of breast and ovarian adenocarcinoma. The tumors are usually large in size (weight on average $2-4$ kilograms, mean diameter $10-20 \mathrm{~cm}$ ), located in the chest in approximately one-third and in the retroperitoneal region in two-thirds of cases $[1,11]$.

\section{Pathogenesis of hypoglycemia associated with non-islet cell tumors}

First hypothesis on pathogenesis of tumor hypoglycemia was increased glucose utilization by large tumors $[1,4]$. However, the crucial event in the development of NICTH seems to be overexpression of the insulin-like growth factor-2 (IGF-2) gene by the tumor. IGF-2 is produced mainly by the liver and binds with receptor IGF2R which is responsible for endocytosis, intracellular hormone transport and degradation of circulating IGF-2. This protein plays an important role in human fetal and post-natal development (growth-regulating, insulin-like, proliferative, mitogenic and antioxidant activity) but whether it has significant physiological function in adults remain unknown [7].

Both IGF-1 and IGF-2 have non-suppressible insulin-like activity (activity which can not be supressed by antiinsulin antibodies) and also act as an insulin sensitizers. They are binding to one of six forms of high affinity IGF binding proteins (IGFBP $1-6$ ) produced by liver, promoting or inhibiting IGF actions. IGF can bind to both IGF-1 receptor and insulin receptor (with a lower afinity compared to insulin, as a secondary via through which this hormone mediates some of its metabolic functions) [12].

IGF-1 and IGF-2 both have glucose lowering potency that is approximately only $5-10 \%$ of insulin's potency [3]. In spite of structural homology with insulin, normal levels of IGF-2 do not cause hypoglycemia. However, plasma concentrations of IGF-1 and IGF-2 can be thousand times greater than insulin in NICTH allowing them to cause hypoglycemia [7]. Hypoglyc- emic activity of IGF- 2 is mediated by stimulation of the insulin receptors and increased glucose utilization (particularly in skeletal muscle) together with the inhibition of glucose release, glycogenolysis and gluconeogenesis in the liver [11].

The IGF-2 gene is located on short arm of chromosome 11 (11p15) close to the insulin gene. IGF-2 is a 67 amino acid polypeptide with $47 \%$ sequence homology with insulin. Post translational prepro IGF-2 contains 180 amino acids with a carboxy terminal peptide of 89 amino acids and a signal peptide of 24 amino acids. Prepro IGF-2 is cleaved to form mature IGF-2 [7].

NICTH is associated with the excessive secretion of incompletely processed posttranslational precursors of IGF-2 (termed 'big' IGF-2) in tumors with aberrant IGF-2 gene transcription and gene expression [1]. In a normal individual, the translated peptide undergoes glycosylation. Posttranslational modifications may be impaired in tumors because of insufficient quantity of enzymes required for this process resulting in big IGF-2. Tumor-derived big IGF-2 primarily forms smaller binary complexes with IGF binding protein, and a greater fraction stays in the free unbound form. Unlike the ternary form, these binary forms can cross the capillary membrane and can act on insulin receptors [3].

This overproduction together with the structural and biochemical homology between IGF-2 and insulin induces secondary changes in the circulating levels of insulin, IGF-1 and IGF-binding proteins resulting in an insulin-like hypoglycemic activity of big IGF-2 $[2,6]$. This results in inhibition of glycogenolysis, gluconeogenesis, decreased lipolysis, and increased peripheral glucose utilization. The release of the counter-regulatory hormones glucagon and growth hormone is suppressed by IGF-2, which in turn magnifies the vulnerability to hypoglycemia in NICTH [1] (Fig. 1). Big IGF-2 also account for elevated glucose consumption in the tumor by autocrine and paracrine effects [5].

Mostly in patients with multiple myeloma we can recognize another pathomechanism of tumor hypoglycemia - autoim- 


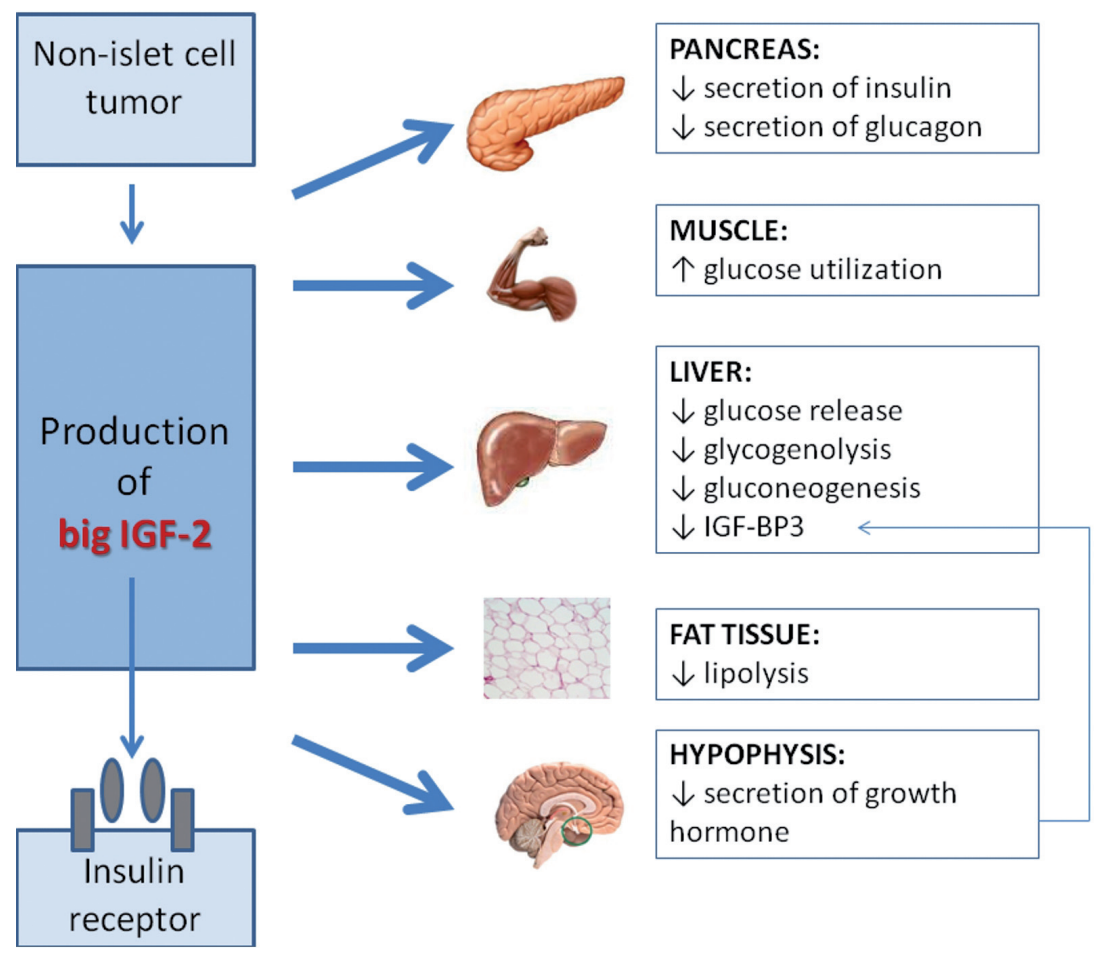

Figure 1. Pathogenesis of tumor hypoglycemia and organ response $[1,5,6]$

mune insulin syndrome (AIS) which is rare in Europe but quite common in Asia (especially Japan). AIS can be easily incorrectly consider to be an insulinoma because of similar clinical features and high levels of insulin. Only the examination of autoantibodies against insulin (in patient who were never treated with an exogenous insulin) or autoantibodies against insulin receptor may reveal the correct diagnosis. Compared to NICTH, AIS may be accompanied not only by fasting hypoglycemia but also reactive postprandial hypoglycemia [13]. The differences between NICTH and AIS are in Table 2.

\section{Clinical symptoms of disease}

Clinical features of NICTH result from recurrent episodes of fasting hypoglycemia and the growth and widespreading of the tumor itself [5].
Andrenergic symptoms (autonomic nervous system's response to hypoglycemia) include nausea, sweating, tremor, palpitations, tachycardia and anxiety. Neuroglycopenic symptoms (low glucose supply to central nervous system) account confusion, impairment of mental concentration, weakness or fatigue, visual disorders, loss of consciousness, coma). Dynkevich et al. $[14,15]$ postulate that neuroglycopenic symptoms are more commonly present than autonomic symptoms due to repeated hypoglycemic events and insidious progression seen with NICTH $[1,15]$.

\section{Diagnosis}

In non-diabetic patients hypoglycemia is defined as a plasma glucose level $<3.3 \mathrm{mmol} / \mathrm{l}(60 \mathrm{mg} / \mathrm{dl})$. The diagnosis of NICTH is established on the basis of the reccurent

Table 2. Clinical and laboratory features of hypoglycemia associated with non-islet cell tumor (NICT), insulinoma and autoimmune insulin syndrome (AIS) $[13,14]$

\begin{tabular}{|c|c|c|c|}
\hline Clinical and laboratory features & NICT & Insulinoma & AIS \\
\hline Hypoglycemia & fasting & fasting & fasting / postprandial \\
\hline Insulin & $\downarrow$ & $\uparrow$ & $\uparrow \uparrow$ \\
\hline C-peptide & $\downarrow$ & $\uparrow$ & $\uparrow \uparrow$ \\
\hline incompletely processed posttranslational precursors of IGF-2 - big IGF-2 & + & - & - \\
\hline Antibodies against insulin or insulin receptor & - & - & + \\
\hline Imaging & + & + & - \\
\hline
\end{tabular}


hypoglycemia, low serum insulin concentrations together with supressed level of C-peptide and IGF-1 and the presence of paraneoplastic secretion of an immature form of IGF-2 (Table 3) [5].

Electrophoresis of plasma IGF-2 (semiquantitative, fast method) reveals the presence of two distinct bands in the patient's serum: a minor band with a low-molecular-weight form corresponding to a normal IGF2 and a major band with a high-molecular-weight form corresponding to an incompletely processed precursor of IGF-2 - big IGF-2 [5]. Total level of IGF-2 may be in physiological range.

Liquid chromatography-mass spectrometry (LC-MS) or immunoassay (ELISA and RIA) may be used for measurement of IGF-2. Size-exclusion acid chromatography and more rapid and equally sensitive western blot may be used for measurement of big IGF-2 (but assays for routine measurement of big IGF-2 are not commercially available) $[5,7]$. Therefore the IGF-2: IGF-1 ratio is used as a surrogate marker for the concentration of big IGF-2. A ratio of $>10$ is considered to be clinically significant and pathognomic for NICTH (Table 3) [4, 7].

If laboratory results suggest NICTH in patient without the history of malignancy, a reasonable next step is cross-sectional imaging of the chest, abdomen, and pelvis to identify a tumor and most reported cases of NICTH involve a tumor in one of these sites [1].

\section{Therapeutics}

The long-term therapeutic strategy is immediate identification and localization of non-islet cell tumor followed by complete resection or at least reduction of the tumor mass; the choice of chemo- or radiotherapy depends upon the primary pathology of the tumor $[1,7]$.

However, this effort is very often not successful or feasible and the principle of the treatment is to increase the plasma glucose level and prevent hypoglycemia [4]. Administration of oral and intravenous glucose or intramuscular and intravenous glucagon is used to maintain euglycemia but both are limited by the need for continuous iv infusion.

Another therapeutic modality are glucocorticoids. Glucocorticoid therapy has been shown to suppress big IGF-2 by converting pre-pro IGF into IGF- 2 in a moderate to high doses $(30-60 \mathrm{mg}$ /day of prednisolone or $4 \mathrm{mg} /$ day of dex-

Table 3 Pathognomonic laboratory findings of non-islet cell tumor hypoglycemia $[5,6,17]$

Low plasma glucose level

Low level of insulin, proinsulin and C-peptide

Decreased IGF-1

IGF-2 may be in physiological range / slightly decreased or increased Increased big IGF-2 (incompletely processed precursors of IGF-2)

IGF-2 : IGF-1 ratio $>10$

Decreased growth hormone amethasone) [7]. Glucocorticoids also provide relief from hypoglycemia by stimulating glyconeogenesis and gluconeogenesis.

According to some authors administration of recombinant human growth hormone (rhGH) is considered to be beneficial in the treatment of NICTH. GH therapy relieves hypoglycemic symptoms by stimulating hepatic gluconeogenesis and glycogenolysis [4]. Although it fails to suppress tumor IGF-2 production [5], preventing interaction with insulin receptor by increasing ternary complex ultimately decreases chances of hypoglycemia. But it also increases total IGF which can be hazardous in the long term [3].

Diazoxide works by activating potassium channels thereby decreasing insulin secretion. That is the reason why it can be particularly used in tumors producing insulin [3]. Octreotide is a somatostatin analogue which inhibits the release of growth hormone, insulin, gastrin, VIP and glucagon. It is more successful in controlling symptoms of VIPomas, carcinoids, and glucoganomas when compared to NICTH [3]. However according to some review diazoxide and octreotide have no role in NICTH $[1,3]$.

\section{Conclusions}

Tumor hypoglycemia caused by the production of incompletely processed precursors of IGF-2 may be a rare reason of fasting hypoglycemia. However increase incidence of malignancies and accumulating literature provides a firm basis for routine IGF-2 laboratory evaluation in patients presenting with spontaneous hypoglycemia with no readily apparent [7]. This should be especially considered in patients suffering from mesenchymal tumors of the chest, abdomen and pelvis.

\section{References}

[[1] BODNAR TW, ACEVEDO MJ, PIETROPAOLO M Management of non-islet-cell tumor hypoglycemia: a clinical review. Journal of Clinical Endocrinology and Metabolism 2013; 99: 713-722. http://dx.doi.org/10.1210/jc.2013-3382

[2] NAUCK MA, REINECKE M, PERRENA, FRYSTYK J, BERISHVILI G et al. Hypoglycemia due to paraneoplastic secretion of insulin-like growth factor-I in a patient with metastasizing large-cell carcinoma of the lung. J Clin Endocrinol Metab. 2007; 92: 1600-1605. http://dx.doi.org/10.1210/ jc. 2006-2573

[3] THOMAS J, KUMAR SC Nonislet Cell Tumor Hypoglycemia. Case Reports in Endocrinology 2013: 308086.

[4] DUTTA P, AGGARWAL A, GOGATE Y, NAHAR U, SHAH VN et al. Non-islet cell tumor-induced hypoglycemia: a report of five cases and brief review of the literature. Endocrinology, Diabetes and Metabolism Case Reports 2013; 2013: 130046. http://dx.doi.org/10.1530/edm-13-0046

[5] MOHAMMEDI K, ABI KHALIL C, OLIVIER S, BENABBAD I, ROUSSEL R et al. Paraneoplastic hypoglycemia in a patient with a malignant solitary fibrous tumor. Endocrinology, Dia- 
betes and Metabolism Case Reports 2014; 5: EDM140026. http://dx.doi.org/10.1530/edm-14-0026

[6] DE GROOT JW, RIKHOF B, VAN DOORN J, BILO HJ, ALLEMAN MA, et al. Non-islet cell tumour-induced hypoglycaemia: a review of the literature including two new cases. Endocr Relat Cancer 2007; 14: 979-993 http://dx.doi. org/10.1677/ERC-07-0161

[7] KHOWAJA A, JOHNSON-RABBETT B, BANTLE J, MOHEET A Hypoglycemia mediated by paraneoplastic production of Insulin like growth factor-2 from malignant renal solitary fibrous tumor - clinical case and literature review. BMC Endocrine Disorders 2014; 14: 49. http://dx.doi. org/10.1186/1472-6823-14-49

[8] SINGH E, VELLA A Hypoglycemia After Gastric Bypass Surgery. Diabetes Spectrum 2012; 25: 4217-4221 http://dx.doi. org/10.2337/diaspect.25.4.217

[9] MIETTINEN M, LASOTA J Gastrointestinal stromal tumors (GIST tumors): definition, occurrence, pathology, differential diagnosis and molecular genetics. Pol. J. Pathol 2003; 54 (1): 3-24.

[10] GRAADT VAN ROGGENA JF, HOGENDOORN PCW Solitary fibrous tumour: the emerging clinicopathologic spectrum of an entity and its differential diagnosis. Current Diagnostic Pathology 2004; 10: 229-235. http://dx.doi.org/10.1016/j.cdip.2004.01.007

[11] SERVICE FJ Hypoglycemic Disorders. N Engl J Med 1995; 332: 1144-1152. http://dx.doi.org/10.1056/ NEJM199504273321707
[12] PUCHE JE, CASTILLA-CORTAZAR I Human conditions of insulin-like growth factor-I (IGF-I) deficiency. Journal of Translational Medicine 2012; 10: 224. http://dx.doi. org/10.1186/1479-5876-10-224

[13] LUPSA BC, CHONG AY, COCHRAN EK, SOOS MA, SEMPLE RK, et al. Autoimmune Forms of Hypoglycemia. Medicine 2009; 88: 141-153. http://dx.doi.org/10.1097/ MD.0b013e3181a5b42e

[14] KAR P, PRICE P, SAWERS S, BHATTACHARYA S, REZNEK $\mathrm{RH}$, et al.Insulinomas may present with normogylcemia after prolonged fasting but glucose-stimulated hypoglycemia. J Clin Endocrinoll Metab. 2006; 91: 4733-4736. http://dx.doi. org/10.1210/jc.2006-1430

[15] DYNKEVICH Y, ROTHER KI, WHITFORD I, QURESHI S, GALIVEETI S, et al. Tumors, IGF-2 and hypoglycemia: insights from the clinic, the laboratory and the historical archive. Endocr Rev. 2013; 34: 798-826. http://dx.doi.org/10.1210/ er.2012-1033

[16] DEDINSKA I, LACA L, MIKLUSICA J, ROSENBERGER J, ZILINSKA Z, et al. Waist circumference as an Independent Risk Factor for NODAT. Annals of transplantation 2015; 20 : 154-159. http://dx.doi.org/10.12659/AOT.892067

[17] BARRA WF, CASTRO G JR, HOFF AO, SIQUEIRA SAC, HOFF PM Symptomatic hypoglycemia related ti inappropriately high IGF-II serum levels in a patient with desmoplastic small round cell tumor. Case Reports in Medicine 2010: Article ID 684045, 3 pages 